\title{
Uso da Farinha Integral da Vagem de Algaroba (Prosopis juliflora (Sw.) D.C.) na Alimentação de Codornas Japonesas
}

\author{
José Humberto Vilar da Silva1, José Nilton Corrêa de Oliveira², Edson Lindolfo da Silva ${ }^{2}$, \\ José Jordão Filho ${ }^{2}$, Marcelo Luís Gomes Ribeiro ${ }^{1}$
}

RESUMO - Um experimento foi realizado para testar a inclusão da farinha integral de vagem de algaroba (FVA) nos níveis de $0 ; 5$; $10 ; 15 ; 20$ e 25\% na alimentação de codornas japonesas. Foram utilizadas 216 codornas com 160 dias de idade e peso vivo de $189 \mathrm{~g}$, distribuídas num delineamento inteiramente ao acaso. As variáveis estudadas foram obtidas em três períodos de 21 dias. O consumo e a massa de ovos do tratamento controle foram superiores aos do tratamento com $25 \%$ de FVA. Excluindo-se o controle, o consumo de ração, produção de ovos, massa de ovos e conversão por massa de ovos foram afetadas de forma quadrática pelos níveis de inclusão de FVA. Recomenda-se a inclusão de FVA em até $15 \%$ ou $150 \mathrm{~g} / \mathrm{kg}$ em rações isoenergéticas e isoprotéicas sem afetar, adversamente, o desempenho de codornas.

Palavras-chave: codornas, desempenho, postura

\section{Use of Integral Mesquite (Prosopis juliflora (Sw.) D.C.) Pods Meal in the Japanese Quails Feeding}

\begin{abstract}
An experiment was conducted to evaluate the inclusion levels of integral mesquite pods meal (MPM) (0, 5, 10, 15, 20 and $25 \%$ ) in diet on laying quail performance. Two hundred and sixteen layer quails with 160 days of age and live weight of $189 \mathrm{~g}$ were allotted to an experimental design completely randomized. The studied variables were obtained in three periods of 21 days. The $25 \%$ of MPM level reduced feed intake and egg mass when compared to control. Except for the control, feed intake, egg production, egg mass production and egg feed mass ratio were quadratically affected. Based on the results of this work, the MPM can be included up to $15 \%$ or $150 \mathrm{~g} / \mathrm{kg}$ in partial corn replacement of isonitrogen and isoenergy diets, without an adverse effect on laying hens quail performance.
\end{abstract}

Kew Words: egg production, performance, quail

\section{Introdução}

A popularidade da criação de codornas vem do pequeno porte, baixo custo, reduzido período para as aves atingirem a maturidade sexual e boa aceitação da carne e ovos pelos consumidores brasileiros. Entretanto, a criação econômica de codornas para a postura depende basicamente de investimentos em pesquisas em quatro áreas básicas do conhecimento: sanidade, genética, ambiência e nutrição (Silva \& Ribeiro, 2001).

A criação de codornas, assim como de outras espécies de aves comerciais, tem na alimentação o principal fator de aumento de custo, representando $70 \%$ ou mais do custo de produção. A busca, portanto, por novos alimentos para compor as rações desta espécie, em substituição àqueles tradicionais, deve priorizar a redução das despesas, a qualidade e a disponibilidade regional do produto.

O milho, que participa em cerca de 60 a $70 \%$ das fórmulas de rações, apresenta baixa produção na região semi-árida brasileira e no período de entressafra torna-se escasso e de preço de aquisição muito elevado. Ao contrário, a algaroba produz frutos no período da entressafra do milho, que poderiam ser melhor utilizados para reduzir o impacto do preço do milho sobre o custo de produção em codornas.

Segundo Silva et al. (2002), toda a produção brasileira de vagem de algaroba se concentra na região Nordeste, num montante superior a 1 milhão de toneladas, com rendimento bruto do produto in natura superior a 12 milhões de dólares, com pequena parte desta produção sendo destinada para a produção da farinha integral de vagem de algaroba (FVA).

A FVA é obtida pela secagem das vagens em secadores durante duas horas a $60-80{ }^{\circ} \mathrm{C}$, e posterior moagem, podendo ser usada em substituição parcial ao milho em rações de aves na região semi-árida do Nordeste (Silva et al., 2001a). As prováveis limitações do emprego da FVA em larga escala em rações de aves são a baixa disponibilidade, excesso de fibra como celulose e lignina, o desconhecimento sobre o 
grau de influência do processamento a calor sobre a qualidade do produto obtido e menor conteúdo de energia que o grão de milho (Silva et al., 2001ab e 2002).

Silva \& Ribeiro (2001) estudando a composição química da farinha integral de vagem de algaroba, observaram valores de 9,6\% PB, 9,47\% FB e $2.806 \mathrm{kcal}$ EMVn. Novamente, Silva et al. (2002) concluíram com base na massa de ovos produzida que o FVA poderia ser incluído em até $13,6 \%$ na ração de poedeiras comerciais, mas nenhum estudo ainda foi realizado com codornas.

O objetivo do presente trabalho foi avaliar a inclusão de níveis crescentes da farinha integral de vagem de algaroba na alimentação de codornas japonesas.

\section{Material e Métodos}

O experimento foi conduzido no Setor de Avicultura do CFT/UFPB/Campus IV, utilizando 216 codornas, com 160 dias de idade. As aves foram pesadas e alojadas em baterias constituídas de gaiolas superpostas de $33 \times 33 \times 9 \mathrm{~cm}$. O galpão onde as aves foram alojadas era coberto com telhas de barro em duas águas, pé direito de $1,8 \mathrm{~m}$ de altura, 4,0 $\mathrm{m}$ de largura e ripado nas laterais.

O delineamento experimental utilizado foi o inteiramente ao acaso com seis tratamentos, constituídos pela inclusão da farinha integral de vagem de algaroba (FVA) em $0 ; 5 ; 10 ; 15 ; 20 ;$ e $25 \%$, com seis repetições. A unidade experimental foi constituída por seis aves.

Tabela 1 - Níveis de inclusão da farinha integral de vagem de algaroba (FVA) e composição química calculada nas rações experimentais

Table 1 - Integral mesquite pods meal (MPM) levels and chemical composition of experimental diets

\begin{tabular}{|c|c|c|c|c|c|c|}
\hline \multirow[t]{2}{*}{ Ingrediente (Ingredient) } & \multicolumn{6}{|c|}{ Níveis de FVA na Ração (\%) (MPM levels in diet) } \\
\hline & 0 & 5 & 10 & 15 & 20 & 25 \\
\hline Milho (Corn) & 59,60 & 54,15 & 48,70 & 43,25 & 37,80 & 32,36 \\
\hline $\mathrm{FVA}(M P M)$ & 0,00 & 5,00 & 10,00 & 15,00 & 20,00 & 25,00 \\
\hline Farelo de soja (Soybean meal) & 23,70 & 23,61 & 23,52 & 23,43 & 23,34 & 23,25 \\
\hline Gluten de milho (Corn gluten) & 7,00 & 7,00 & 7,00 & 7,00 & 7,00 & 7,00 \\
\hline Calcário (Limestone) & 5,69 & 5,66 & 5,62 & 5,59 & 5,56 & 5,53 \\
\hline Fosf. bicálc. (Phosphate dicalcium) & 1,33 & 1,35 & 1,37 & 1,39 & 1,41 & 1,43 \\
\hline DL-Metionina (DL-Methionine) & 0,14 & 0,16 & 0,17 & 0,19 & 0,21 & 0,22 \\
\hline $\mathrm{L}-\mathrm{Lisina} \cdot \mathrm{HCl}(\mathrm{L}-$ Lysine $\cdot \mathrm{HCl})$ & 0,01 & 0,01 & 0,01 & 0,02 & 0,02 & 0,02 \\
\hline Cloreto de colina (Choline Chloride) & 0,15 & 0,15 & 0,15 & 0,15 & 0,15 & 0,15 \\
\hline Premix vitamínico ${ }^{1}$ (Mineral mix) & 0,15 & 0,15 & 0,15 & 0,15 & 0,15 & 0,15 \\
\hline Premix mineral $^{2}$ (Vitamin mix) & 0,10 & 0,10 & 0,10 & 0,10 & 0,10 & 0,10 \\
\hline Óleo vegetal (Vegetal oil) & 1,84 & 2,37 & 2,90 & 3,42 & 3,95 & 4,48 \\
\hline Sal comum (Salt) & 0,29 & 0,29 & 0,29 & 0,30 & 0,30 & 0,30 \\
\hline $\mathrm{BHT}^{3}$ & 0,01 & 0,01 & 0,01 & 0,01 & 0,01 & 0,01 \\
\hline \multirow[t]{2}{*}{ Total } & 100,00 & 100,00 & 100,00 & 100,00 & 100,00 & 100,00 \\
\hline & \multicolumn{6}{|c|}{ Composição calculada 4 (Calculated composition) } \\
\hline Matéria seca (\%) (Dry matter) & 85,94 & 86,29 & 86,64 & 86,99 & 87,33 & 87,68 \\
\hline Proteína bruta (\%) (Crude protein) & 19,90 & 19,90 & 19,90 & 19,90 & 19,90 & 19,90 \\
\hline $\operatorname{EM}(\mathrm{kcal} / \mathrm{kg})(M E)$ & 3000 & 3000 & 3000 & 3000 & 3000 & 3000 \\
\hline Cálcio (\%) (Calcium) & 2,55 & 2,55 & 2,55 & 2,55 & 2,55 & 2,55 \\
\hline Fósforo dispon. (\%) (Available P) & 0,35 & 0,35 & 0,35 & 0,35 & 0,35 & 0,35 \\
\hline Met $+\operatorname{cis}(\%)$ (Methionine + cystine $)$ & 0,76 & 0,76 & 0,76 & 0,76 & 0,76 & 0,76 \\
\hline Lisina $(\%)($ Lysine $)$ & 0,70 & 0,70 & 0,70 & 0,70 & 0,70 & 0,70 \\
\hline Sódio (\%) (Sodium) & 0,15 & 0,15 & 0,15 & 0,15 & 0,15 & 0,15 \\
\hline Fibra bruta (\%) (Crude fiber) & 2,67 & 3,58 & 4,48 & 5,39 & 6,29 & 7,20 \\
\hline \multicolumn{7}{|c|}{ 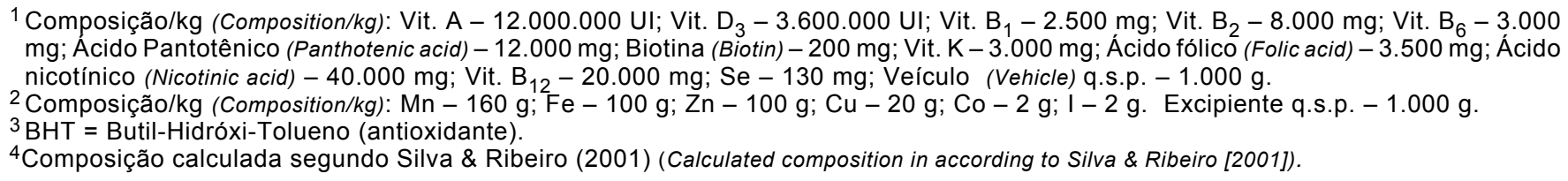 } \\
\hline
\end{tabular}

R. Bras. Zootec., v.31, n.4, p.1789-1794, 2002 
As rações isoprotéicas e isocalóricas (Tabela 1) foram formuladas de acordo com as recomendações de Silva \& Ribeiro (2001). As aves foram submetidas a fotoperíodo natural e alimentadas com ração e água à vontade durante três subperíodos de 21 dias.

As variáveis estudadas foram o peso vivo, consumo de ração, produção de ovos, peso e massa de ovos, conversão alimentar por massa de ovos e pigmentação da gema dos ovos. A massa de ovos foi estimada pelo produto entre a porcentagem de produção de ovos (ave/dia) e o peso dos ovos (g/ave/dia). Enquanto, a conversão alimentar pela massa de ovos foi obtida pela relação entre o consumo de ração (g/ave/dia) e a massa de ovos. Enquanto a pigmentação da gema foi avaliada por intermédio do leque colorimétrico da Roche.

As análises estatísticas foram realizadas pelo SAEG desenvolvido na Universidade Federal de Viçosa - UFV (1983). Os níveis ótimos de farinha integral de vagem de algaroba das rações foram obtidos pela regressão quadrática $(\mathrm{P}<0,05)$, excluindo-se o nível zero de FVA na ração. As médias de cada nível de FVA na ração foram comparadas com as do tratamento controle pelo teste de Dunnet $(\mathrm{P}<0,05)$. O modelo estatístico utilizado foi o seguinte:

$$
\mathrm{yij}=\mathrm{m}+\mathrm{NFVAi}+\mathrm{eij}
$$

em que: yij = observação relativa ao efeito do nível de FVAi na unidade experimentalj; $m=$ média experimental; NFVAi = efeito do i-éssimo nível de FVA na ração, sendo $\mathrm{i}=0,5,10,15,20$ e $25 \%$; eij $=$ erro experimental NID $(0 ; s)$.

\section{Resultados e Discussão}

O nível de $25 \%$ de farinha integral de vagem de algaroba afetou o consumo de ração $(\mathrm{P}<0,05)$, mas não alterou o peso vivo das codornas, em comparação com o tratamento controle (Tabela 2). Houve efeito quadrático da adição de FVA sobre o consumo $(\mathrm{P}<0,01)$ corroborando com o resultado obtido por Silva et al. (2002) com poedeiras comerciais. O alto teor de fibra presente na FVA foram os prováveis fatores relacionados com os resultados obtidos no presente estudo.

Segundo Silva et al. (2001b e 2002), embora a FVA apresente teor de PB semelhante ao milho, é mais rico em celulose e lignina, que não são digeridas pelas enzimas endógenas presentes no trato gastrointestinal de aves, podendo retardar a taxa de passagem do alimento prolongando o efeito do enchimento sobre a distensão do trato gastrointestinal. Segundo Mcbee (1977) nenhum microorganismo celulolítico foi isolado nos cecos de aves. Noblet \& Le Goff (2001) afirmaram que a adição de um ingrediente fibroso interfere na digestibilidade da ração e, segundo Rérat (1978) o aumento da celulose em dietas de ratos afetou a digestibilidade da matéria seca.

Posteriormente, Silva \& Ribeiro (2001) detectaram um pequeno atraso na taxa de passagem de uma mistura contendo $30 \%$ de FVA em substituição a mesma quantidade de uma ração à base de milho e farelo de soja (63 vs. $60 \mathrm{~min}$ ).

Excluindo-se o tratamento controle, o consumo de ração foi afetado de forma quadrática $(\mathrm{P}<0,05)$

Tabela 2 - Peso vivo (PV), consumo de ração (CR) e produção de ovos (PR) em codornas, em função dos níveis de FVA na ração e resumo da análise de variância (ANVA)

Table 2 - Live weight (LW), feed intake (FI) and egg production (EP)of quail layer, according to the integral mesquite pods meal levels and ANOVA result

\begin{tabular}{|c|c|c|c|}
\hline $\begin{array}{l}\text { \%FVA } \\
\text { Integral mesquite pods meal levels }\end{array}$ & $\mathrm{PV}(L W)$ & $\mathrm{CR}(F I)$ & $\mathrm{PR}(E P)$ \\
\hline 0 & $193,50^{\mathrm{a}}$ & $26,97^{\mathrm{a}}$ & $79,89^{\mathrm{a}}$ \\
\hline 5 & $186,50^{\mathrm{a}}$ & $24,72^{\mathrm{a}}$ & $67,06^{\mathrm{a}}$ \\
\hline 10 & $190,99^{\mathrm{a}}$ & $24,91^{\mathrm{a}}$ & $68,25^{\mathrm{a}}$ \\
\hline 15 & $192,38^{\mathrm{a}}$ & $26,05^{\mathrm{a}}$ & $82,67^{\mathrm{a}}$ \\
\hline 20 & $191,11^{\mathrm{a}}$ & $25,66^{\mathrm{a}}$ & $74,46^{\mathrm{a}}$ \\
\hline 25 & $190,72^{\mathrm{a}}$ & $24,03^{\mathrm{b}}$ & $63,36^{\mathrm{a}}$ \\
\hline \multicolumn{4}{|l|}{ ANVA (Anova) } \\
\hline Nível FVA (MPM levels) & $\mathrm{ns}$ & $\mathrm{ns}$ & * \\
\hline Linear (Linear) & $\mathrm{ns}$ & $\mathrm{ns}$ & $\mathrm{ns}$ \\
\hline Quadrático (Quadratic) & $\mathrm{ns}$ & $* * *$ & $* * *$ \\
\hline CV $(\%)$ & 3,45 & 7,42 & 16,23 \\
\hline
\end{tabular}

a,b Médias seguidas de letras distintas nas colunas, diferem pelo teste de Dunnet $(P<0,05)$ (Means followed by different letters, are different by Dunnet test).

${ }^{*} \mathrm{P}<0,10 ;{ }^{* * *} \mathrm{P}<0,01$.

R. Bras. Zootec., v.31, n.4, p.1789-1794, 2002 


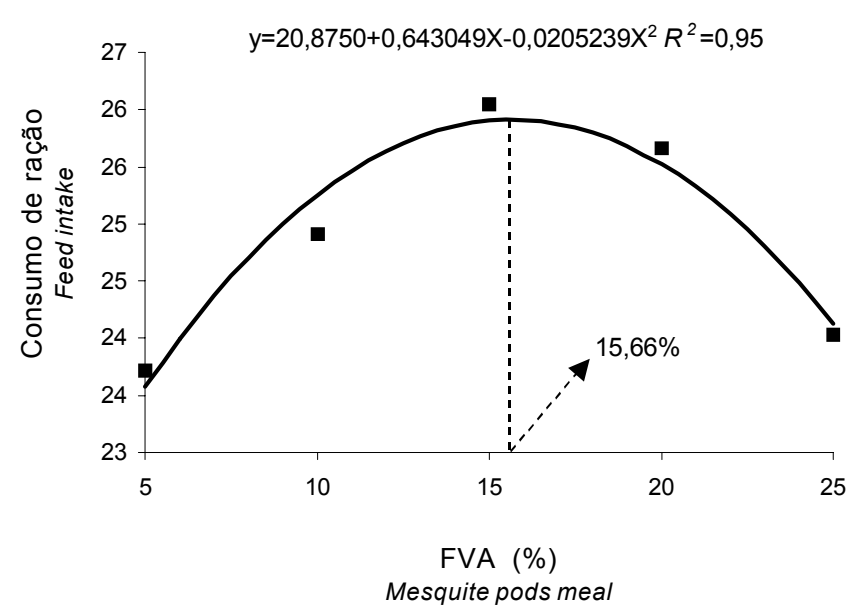

Figura 1 - Consumo de ração de codornas, em função do nível de FVA na ração.

Figure 1 - Feed intake of Japanese quail, in fuction of mesquite pods meal rates in the diet.

pelos níveis de inclusão de FVA na ração, sendo o nível ótimo de 15,66\% (Tabela 2; Figura 1). Resultado semelhante foi obtido por Silva et al. (2002), que observaram consumo máximo de poedeiras comerciais, quando o FVA foi incluído em 15,9\% em substituição parcial ao milho na ração.

Portanto, o aumento da fibra deve ser a principal explicação para a queda do consumo de ração, à medida que o nível de inclusão da FVA se aproximou do valor máximo de $25 \%$ na ração.

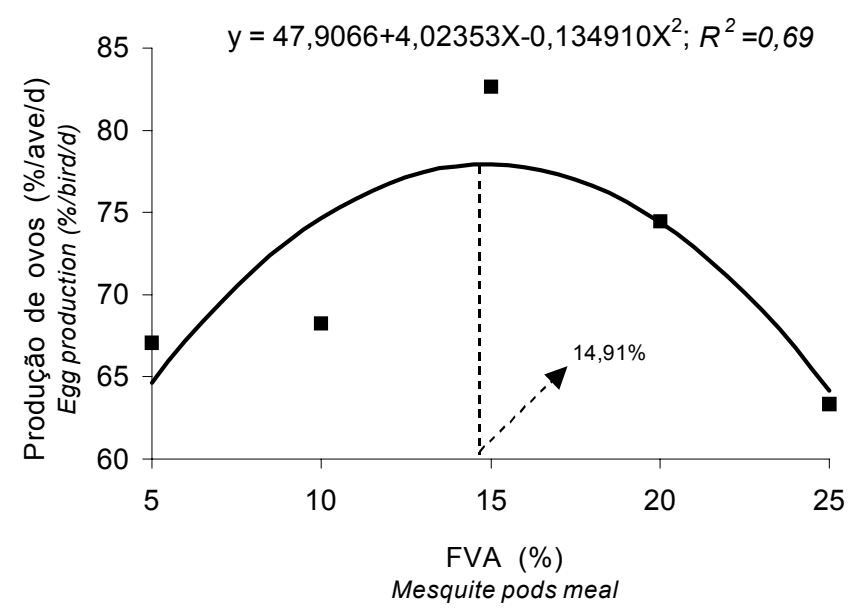

Figura 2 - Produção de ovos de codornas em função do nível de FVA na ração.

Figure 2 - Egg production of Japanese quails, in fuction of mesquite pods meal rates in the diet.
Foram detectados efeitos quadráticos $(\mathrm{P}<0,05)$ dos níveis da farinha integral de algaroba na ração sobre a produção de ovos com nível ótimo de inclusão da FVA em torno de $14,91 \%$ na ração (Tabela 2; Figura 2); e sobre a massa de ovos, com nível ótimo de inclusão de FVA em 14,81\% (Tabela 3; Figura 3).

O declínio do consumo e conseqüente redução do aporte de nutrientes para atender as necessidades de máximo desempenho foi a provável explicação para a diminuição da produção de ovos das aves, com o aumento da proporção de FVA na ração.

Silva et al. (2002), trabalhando com poedeiras comerciais, obtiveram máxima produção de ovos com $13,8 \%$ e máxima massa de ovos com $14,1 \%$ de inclusão de FVA na ração. As semelhanças em termos de tolerância aos níveis de FVA na ração parecem mostrar que as codornas podem ser usadas satisfatoriamente como possíveis modelos biológicos para testar alimentos a serem usados na alimentação de galinhas poedeiras com ganhos econômicos importantes.

O peso dos ovos e a pigmentação da gema não foram afetados pelos níveis de inclusão da FVA na ração, entretanto a conversão alimentar por massa de ovos foi de forma quadrática (Tabela 3; Figura 4) $(\mathrm{P}<0,10)$, sendo o melhor resultado obtido com $14,45 \%$ da FVA na ração. Este resultado concordou com aquele de 13,6\% de inclusão da FVA na ração de poedeiras comerciais (Silva et al., 2002).

A piora da conversão alimentar por massa de

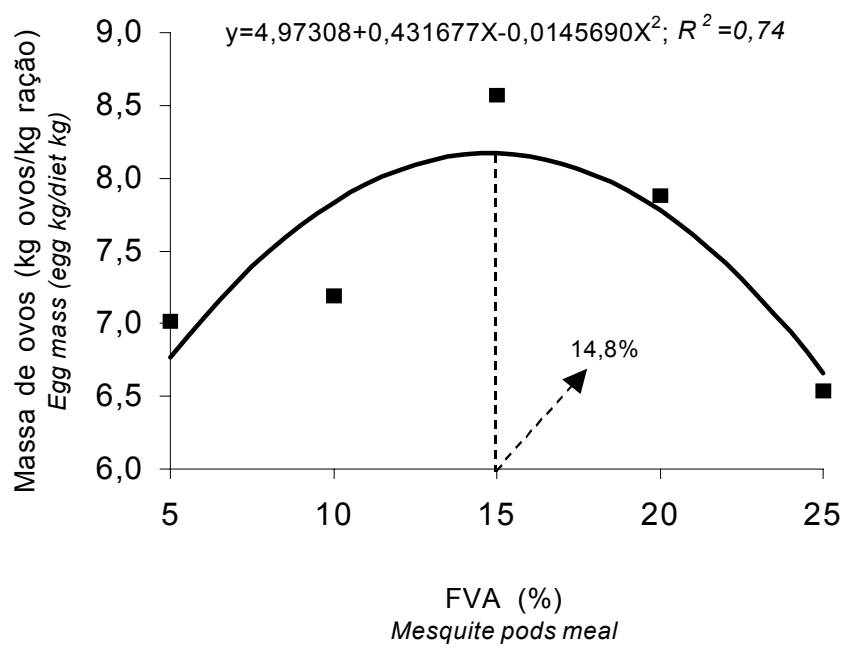

Figura 3 - Massa de ovos produzida por codornas em função do nível de FVA na ração.

Figure 3 - Egg mass of Japanese quails, in fuction of mesquite pods meal rates in the diet.

R. Bras. Zootec., v.31, n.4, p.1789-1794, 2002 
Tabela 3 - Peso (PO), massa (MO) e conversão por massa de ovos (CM), pigmentação da gema (PIG) e resultado da ANVA em função dos níveis de FVA na ração de codornas japonesas

Table 3 - Egg weight (EW), egg mass (EM), feed egg mass conversion (EMC), egg yolk color (EC) and ANOVA result of the effects of integral mesquite pods meal rates in corn replacement in hen quail diets

\begin{tabular}{|c|c|c|c|c|}
\hline \multicolumn{5}{|l|}{ Mesquite pods meal rates } \\
\hline 0 & $10,72^{\mathrm{a}}$ & $8,56^{\mathrm{a}}$ & $3,23^{\mathrm{a}}$ & 4,70 \\
\hline 5 & $10,48^{\mathrm{a}}$ & $7,02^{\mathrm{a}}$ & $3,54^{\mathrm{a}}$ & 4,83 \\
\hline 10 & $10,56^{\mathrm{a}}$ & $7,19^{a}$ & $3,50^{\mathrm{a}}$ & 5,58 \\
\hline 15 & $10,39^{\mathrm{a}}$ & $8,57^{\mathrm{a}}$ & $3,07^{\mathrm{a}}$ & 5,61 \\
\hline 20 & $10,61^{\mathrm{a}}$ & $7,88^{a}$ & $3,32^{\mathrm{a}}$ & 5,06 \\
\hline 25 & $10,31^{\mathrm{a}}$ & $6,54^{b}$ & $3,75^{\mathrm{a}}$ & 5,25 \\
\hline \multicolumn{5}{|l|}{ ANVA (Anova) } \\
\hline Nível FA (MPM rates) & ns & $* *$ & $\mathrm{~ns}$ & $\mathrm{~ns}$ \\
\hline Linear (Linear) & $\mathrm{ns}$ & $\mathrm{ns}$ & $\mathrm{ns}$ & $\mathrm{ns}$ \\
\hline Quadrático (Quadratic) & ns & $* * *$ & $*$ & ns \\
\hline $\mathrm{CV}(\%)$ & 3,45 & 15,76 & 17,07 & 19,10 \\
\hline
\end{tabular}

a,b Médias seguidas de letras distintas nas colunas, diferem pelo teste de Dunnet $(P<0,05)$ (Means followed by different letters are different by Dunnet test). ${ }^{*} \mathrm{P}<0,10 ;{ }^{* *} \mathrm{P}<0,05 ;{ }^{* *} \mathrm{P}<0,01$.

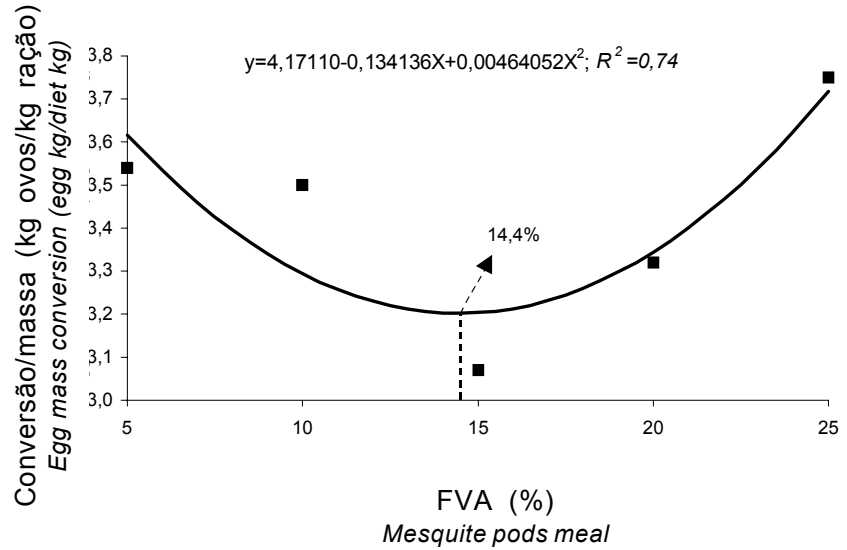

Figura 4 - Conversão alimentar de codornas em função do nível de FVA na ração.

Figure 4 - Feed egg mass conversion of quail in fuction of mesquite pods meal rates in diet.

ovos quando a FVA foi incluída acima de 14,4\% sugere redução da eficiência de utilização da ração pelas aves, sendo o aumento do conteúdo de fibra da ração, provavelmente, o principal fator envolvido.

Na Tabela 1, pode-se observar que a inclusão da FVA elevou a fibra bruta da ração de 2,7 para $7,2 \%$. Segundo Noblet \& Le Goff (2001), Bach Knudsen (2001) e Wenk (2001), a presença de excesso de fibra na ração afeta o aproveitamento de todos os ingredientes presentes na mesma. Del Valle et al.
(1983) indicaram que o alto teor de fibra da vagem de algaroba deve limitar o acesso das proteases aos locais das células onde as proteínas estão presentes

O maior conteúdo de fibra insolúvel presente na FVA, segundo Silva et al. (2002), deve afetar a dinâmica da taxa de passagem pelo trato gastrointestinal das aves, aumentando a viscosidade da digesta e reduzindo a eficiência de aproveitamento dos nutrientes da FVA e de toda a ração.

Silva \& Ribeiro (2001) observaram maior ocorrência de umidade nas excretas de codornas alimentadas com uma mistura contendo $30 \%$ da FVA, em substituição correspondente a ração basal constituída pelo milho e farelo de soja, que sugere possível aumento da viscosidade intestinal, declínio do aproveitamento do alimento e ocorrência de diarréias nas aves. A maior concentração de celulose e lignina da FVA (Silva et al., 2001b), a presença de sacarose como principal carboidrato na polpa e galactomananos nas sementes que reagem com a água e formam soluções altamente viscosas (Grados \& Cruz, 1996), merecem ser mencionados como importantes fatores antinutricionais presentes na FVA.

\section{Conclusão}

Com base no resultado da conversão alimentar por massa de ovos produzida, conclui-se que a inclusão da farinha integral de vagem de algaroba em até $15 \%$ em rações isoprotéicas e isoenergéticas, não afeta o desempenho de codornas. 


\section{Literatura citada}

BACH KNUDSEN, K.E. The nutritional signigicance of "dietary fiber" analysis. Animal Feed Science and Technology, v.90, p.3-20, 2001.

DEL VALLE, F.R., ESCOBEDO, M., MUÑOZ, M.J. Chemical and nutritional studies on mesquite beans (Prosopis juliflora). Journal of Food Science, v.48, p.914-919, 1983.

GRADOS, N.; CRUZ, G. New approaches to industrialization of algarobo (Prosopis pallida) pods in Peru. In: FELKER, P., MOSS, J. (Eds.). Workshop Prosopis: semiarid fuelswood and forage tree building consensus for the disenfranchised. Washington, D.C.: Texas AM University, 1996. p.25-42.

NOBLET, J.; Le GOFF, G. Effect of dietary fibre on the energy value of feeds for pigs. Animal Feed Science Technology, v.90, p.35-52, 2001.

McBEE, R.H. Fermentation in the hind gut. In: CLARKE, R.T.J.; BAUCHOP, T. (Eds.). Microbial ecology of the gut. London: Academy Press, 1977. p.185-222.

RÉRAT, A. Digestion and absorption of carbohydrates and nitrogenuos matters in the hindgut of the omnivorous nonruminants animal. Journal of Animal Science, v.46, p.1808-1837, 1978.

SILVA, E.L.; SILVA, J.H.V.; JORDÃO FILHO, J. et al. Uso do farelo de algaroba (Prosopis juliflora (Sw.) DC.) processada a calor na alimentação de poedeiras comerciais. In: APINCO, 2001, Campinas. Anais...Campinas: FACTA, 2001a. p.21.

SILVA, J.H.V.; RIBEIRO, M.L.G. Tabela nacional de exigência nutricional de codornas. Bananeiras, $\mathrm{PB}$ : DAP/UFPB, 2001. 21p.

SILVA, J.H.V.; SILVA, E.L.; JORDÃO FILHO, J. et al. Valores energéticos e efeitos da inclusão do farelo de vagem de algarobeira (P.juliflora (Sw.) D.C.) em substituição ao milho em rações de poedeiras comerciais. Revista Brasileira de Zootecnia, v. 61, 2002. (no prelo).

SILVA, J.H.V.; TOLEDO, R.S.; ALBINO, L.F.T. Composição química e valores energéticos da semente de cunhã (Clitorea ternatea L.) feijão guandú (Cajanus cajan) e da vagem de algaroba (Prosopis juliflora (Sw.) D.C.) para aves. In: REUNIÃO ANUAL DA SOCIEDADE BRASILEIRA DE ZOOTECNIA, 38., 2001, Piracicaba. Anais... Piracicaba: Sociedade Brasileira de Zootecnia, 2001b. p.891-892.

UNIVERSIDADE FEDERAL DE VIÇOSA - UFV. Manual do SAEG (Sistema de análises estatísticas e genéticas). Viçosa, MG: Universidade Federal de Viçosa, 1983. 380p.

WENK, C. The role of dietary fibre in the digestive physiology of the pig. Animal Feed Science Technology, v.90, p.21-33, 2001.

Recebido em: 23/11/01

Aceito em: 01/04/02 